\title{
The effects of vacuum cooling to post-pasteurized honey on diastase enzyme activity and physical properties of Riau Forest Honey
}

\section{Silvi Astri Cahyani ${ }^{*}$, Anang Lastriyanto, Sandra Malin Sutan and Sumardi}

Department of Agricultural Engineering, Faculty of Agricultural Technology, Brawijaya University, Jl. Veteran, Malang East Java, Indonesia

\begin{abstract}
Honey is defined as a traditional natural liquid which usually has a sweet taste derived from the nectar of flowers. The main component of honey is a natural saturated sugar solution consisting of a mixture of complex carbohydrates and contains various important micro-nutrients such as vitamins, minerals, enzymes, and organic compounds. These micro-nutrients are very susceptible to damage during the honey processing process. In this study, a cooling method in the form of vacuum cooling was applied with the aim of maintaining the micro-nutrients in honey. Vacuum cooling that is applied after the pasteurization process aims to release the latent heat trapped in the honey in a relatively short time and minimize damage to micronutrient, especially the diastase enzyme. The research design consisted of 2 factors, namely the volume chamber consisting of $12.5 \%$, $25 \%$, and $50 \%$. The second factor is the cooling method which consists of conventional and vacuum cooling. The samples from the research were tested on diastase enzyme activity and the physical properties of honey such as moisture content, density, and acidity. The results showed that cooling with the vacuum cooling method had lower water content, low acidity, high density, and better diastase enzyme activity compared to conventional cooling.
\end{abstract}

\section{Article History}

Received July 17, 2021

Accepted Nov 06, 2021

\section{Keyword}

Vacuum cooling,

Honey,

Moisture content,

Diastase enzyme

\section{Introduction}

Indonesia is a tropical country with large biodiversity include bees which produce various type of honey. Honey is a natural ingredient in the form of a thick liquid with a slightly sweet taste produced by honey bees from flower nectars (floral nectar) (1). Many regions in Indonesia such as Sumatra, Sulawesi, Java, Nusa Tenggara and others produce different type of honey. Honey production in Indonesia is dominated by forest honey produced by Apis dorsata Fabr (about 70\%) and cultivated honey produced by Apis Malifera and Apis Cerana (about 30\%). Riau Forest honey is one type of honey that comes from various kinds of flower nectar in the Riau Forest. Pure forest honey tends to have high water content due to high humidity in the region. In addition, honey is hygroscopic material which easily absorb water.

The chemical and nutritional contents of honey have long been trusted by the wider community because it has therapeutic properties that can help cure various diseases and can be used as a natural ingredient in foods and drinks. The micronutrient contents of honey which include various types of vitamins, minerals, enzymes, organic compounds, free 
amino acids and various volatile compounds is the most important component in honey. These micronutrients are very susceptible to damage during processing, especially at high temperatures. The use of high temperatures in the honey processing is generally carried out with the aim of reducing the water content in order to avoid the proliferation of microbes and fermentation process. Therefore, it is necessary to carried out processing steps using the correct methods in order to obtain high quality honey.

There are two main processing steps that are usually carried out namely pasteurization to kill harmful microorganisms and evaporation to reduce the water content. The pasteurization process for honey should not be done using high heat and the process should be carried out in a very short time to avoid inactivation of desirable enzymes such as diastase enzyme. Pasteurization temperature for honey is $70^{\circ} \mathrm{C}$ or below to avoid the destruction of micronutrients. In addition, the heat contained in honey after the pasteurization process can also cause undesirable effects. Therefore, cooling process must be done immediately after pasteurization in order to protect the color, taste, enzyme content, and other biological substances in honey (2). The conventional cooling process generally takes a long time which can pose risk of contamination and water absorption.

Vacuum cooling can provide fast cooling and is suitable to be used for liquid and porous products as has been done for sauce and soup products $(3,4)$. Therefore, in this study, vacuum cooling was applied. This study compared physical properties and enzymatic properties of vacuum cooled and conventional cooled honey. Parameters measured include water content, acidity, density, enzymatic activity.

\section{Materials and Methods}

The main ingredient used was pure Riau forest honey, which was obtained directly from local honey breeders. Meanwhile, the tools used in this research include liter capacity vacuum cooling equipped with temperature automation, moisture analyzer to measure moisture content, stopwatch, digital scale, quartz cuvette, Nanotech heater one liter NT1703, Visible Spectrophotometer 721, digital scale and supporting equipment. Other materials used are iodine, potassium iodide, distilled water, acetic acid, sodium acetate, $\mathrm{NaCl}, \mathrm{NaOH}$ and soluble amylum.

The research was carried out in three stages, namely honey processing, honey sampling and honey sample testing. Honey processing was carried out in two stages including pasteurization and cooling processes. The cooling process were carried out using two different techniques, namely conventional cooling and vacuum cooling. Sampling was carried out on raw samples and at each processing steps (after pasteurization, after conventional cooling or after vacuum cooling). The processed samples obtained were placed into air tight bottles and stored at room temperature to avoid changes in physical and chemical properties. Sample testing were done to determine the physical properties and enzyme activity before the evaporation process and after the evaporation process. Physical properties measured include moisture content, acidity and density.

\subsection{Water Content}

Water content tests are carried out in every honey processing process, starting from raw honey, pasteurization, vacuum cooling, and conventional cooling. Water contents in the 
honey samples were measured using the Shimadzu Moisture Analyzer MOC 120. The standard used in the analysis of water content in honey is SNI 8664:2018 regarding honey.

\subsection{Acidity}

The acidity tests were carried out using acid-base neutralization method. Honey samples were carefully weighed $(10 \mathrm{~g})$, placed into $250 \mathrm{ml}$ Erlenmeyer and dissolved in 75 $\mathrm{ml}$ distilled water and added with 4-5 drops of PP indicator, then titrated with $0.1 \mathrm{~N} \mathrm{NaOH}$ solution until a stable color was attained for about 10 seconds. The volume of $0.1 \mathrm{~N} \mathrm{NaOH}$ used during titration was noted. The acidity in honey was calculated using equation:

$$
\text { Acidity }(\mathrm{ml} \mathrm{NaOH} / \mathrm{Kg})=\frac{\mathrm{a} \times \mathrm{b}}{\mathrm{c}} \times 1000
$$

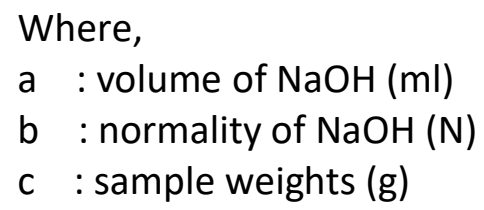

\subsection{Density}

Density $\left(\mathrm{Kg} / \mathrm{m}^{3}\right)$ measurements were carried out using pycnometer. This procedure determined the density based on the mass of honey in the pycnometer (determine using precision digital scale) (5). Calculation of sample density was done using equation:

$$
\rho=\frac{w 2-w 1}{V_{p}}
$$

Where,

$\rho$ : Density $\left(\mathrm{Kg} / \mathrm{m}^{3}\right)$

w1 : Mass of empty pycnometer (g)

w2 : Mass of pycnometer containing fluid (g)

$\mathrm{V}_{\mathrm{p}}$ : Volume of Pycnometer ( $\mathrm{ml}$ )

\subsection{Diastase Enzyme Activity}

In this research, diastase enzyme activity was determined using the Schade method. The materials used in this test were iodine, potassium iodide, distilled water, acetate buffer, sodium chloride and starch. Soluble amylum was dissolved in distilled water and then heat it in boiling water for 5 minutes. lodine reagent was prepared from a mixture of iodine, potassium iodide and distilled water.

Sample preparation using the Schade method was carried out by mixing $5 \mathrm{~g}$ of honey sample with aquadest. The solution was buffered before adding $\mathrm{NaCl}$ and heated at $40^{\circ} \mathrm{C}$ for 15 minutes. Meanwhile, starch solution was heated in a separate beaker at $40^{\circ} \mathrm{C}$ for 15 minutes. The honey solution and the starch solution were mixed and heated again at $40^{\circ} \mathrm{C}$. Sampling was done every 5 minutes for 15 minutes. About $0.5 \mathrm{ml}$ of sample solution was added and mixed into the iodine reagent and absorbance was measured at $660 \mathrm{~nm}$ using a visible spectrophotometer 721 . Absorbance data and heating time were used to construct a linear regression equation. The regression equation was used to determine the time $(x)$ 
required to achieve the specified absorbance of 0.235 (1). The $x$ value was entered into the following equation:

$$
\mathrm{DN}=\frac{300}{\mathrm{x}}
$$

Where,

DN = Diastase value

$\mathrm{x}=$ Time needed to reach absorbance 0.235

\section{Results and Discussion}

\subsection{Water Content}

Water content is one of the important parameters that affect the quality of honey. Like in the Ethiopian, honey is divided into 3 grades based on the moisture content, namely grade $\mathrm{A}$ honey has moisture content of less than $19 \%$ while grade $\mathrm{C}$ has a moisture content of more than $20 \%(6)$. Water can affect the quality, density and viscosity of honey.

Figure 1 shows the value of water content of honey produce from processes using two types of cooling techniques, namely conventional and vacuum cooling. Water contents of all treatments were lower than that of raw honey. It can also be seen from Figure 1 that, honey processed using vacuum cooling treatment had significantly lower water content compared to those of other treatments. The vacuum cooling process can reduce water content since boiling point of water is low at low pressure. Evaporative cooling technique that can be applied to various products without damaging their physical or chemical content (7). The vacuum cooling process can produce honey with low moisture content without the use of heat in the process. Therefore, vacuum cooling process can replace the evaporation process that involves heat that causes damage to the micronutrient in honey.

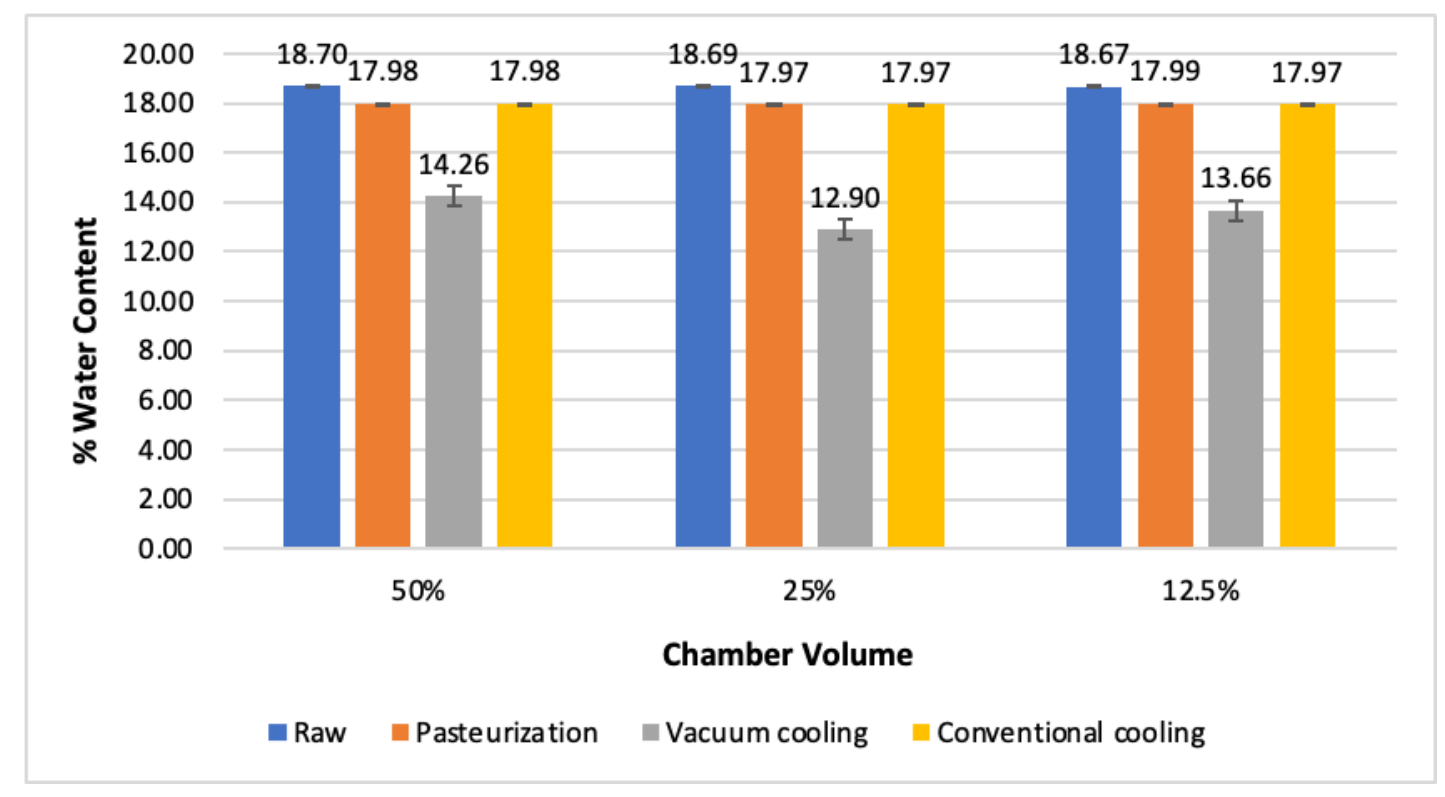

Figure 1. Riau forest honey water content. 
The water content of honey must meet the required moisture content stipulated in Indonesia standard (SNI). Based on the regulation the maximum water content of honey is $22 \%$. At moisture content below the maximum level, the shelf life will be longer and the occurrence of fermentation can be avoided (8). The lowest moisture water content of Riau honey was found in vacuum cooling sample (12.5\%) at $25 \%$ volume chamber. The water content in all samples of Riau Forest honey before and after the pasteurization process and the cooling process had met the SNI standard on honey $(<22 \%)$ so the quality can be considered as high.

\subsection{Density}

Density can be used as a parameter to determine the quality of honey. The part of the honey that has low density will float at the top, while honey with high density will sink at the bottom. The density of honey is influenced by several factors such as intermolecular attractions, ambient temperature, and the size and number of dissolved molecules (9).

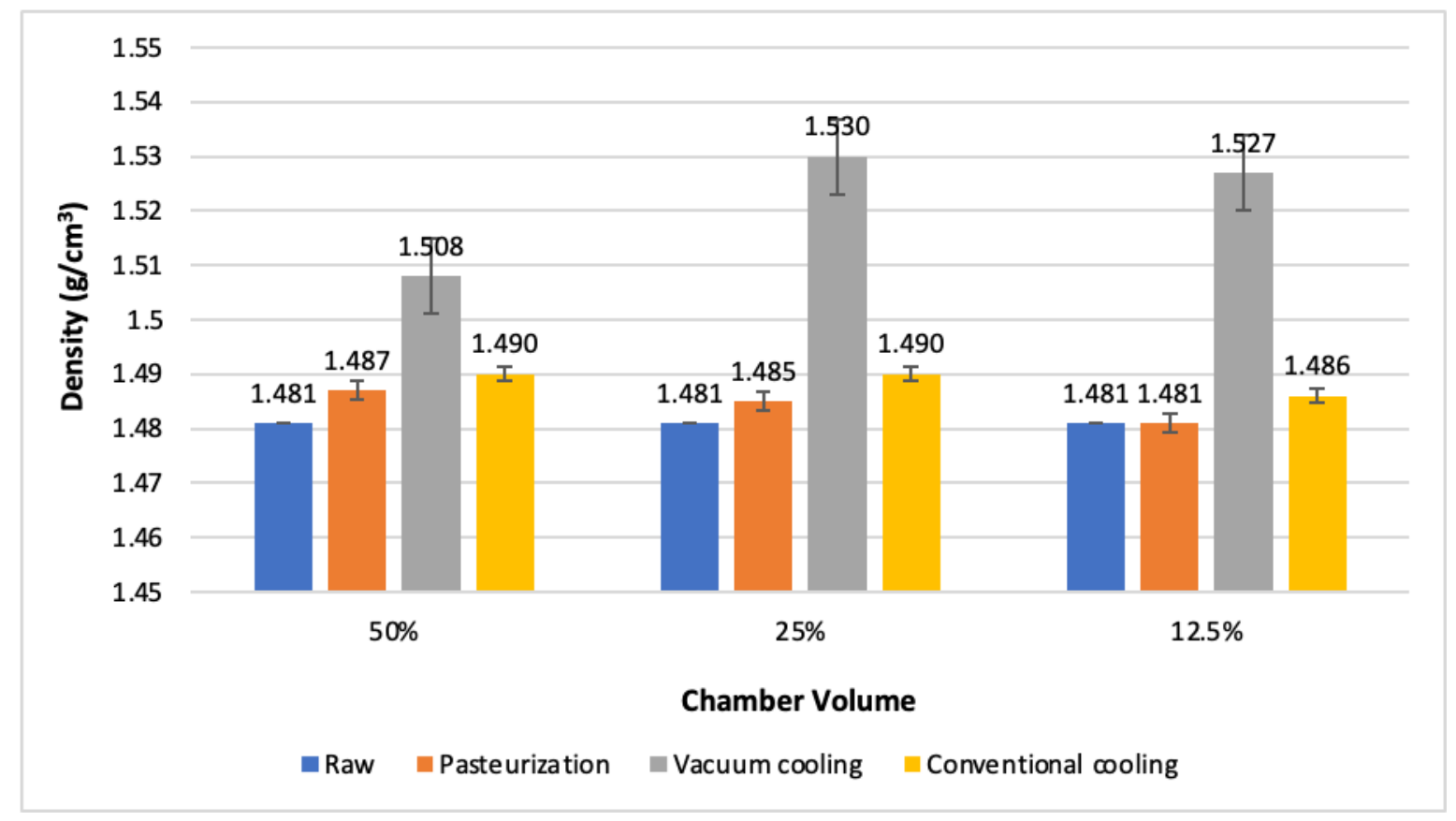

\section{Figure 2. Riau forest honey density.}

Figure 2 shows the density data for all treatments of Riau Forest honey. It can be seen from Figure 2 that for pasteurized and vacuum treatments, the smaller the chamber volume, the lower the density. However, reverse trend was observed for vacuum cooling. This trend can be related to the trend observed for water content, where the lower the moisture content, the higher the density, and vice versa (10). It is important to note that the different in density after pasteurization (measured right after pasteurization in hot condition) and cooling was also significantly affected by temperature.

The highest density value was obtained from cooling process using vacuum cooling method and the chamber volume of $250 \mathrm{ml}$. During the vacuum cooling process, the amount of water evaporated was related to the amount of heat released in the vacuum cooling. 


\subsection{Diastase Enzyme Activity}

Diastase enzyme is an enzyme added by bees during honey maturation process. This enzyme can convert complex carbohydrates (polysaccharides) into simple carbohydrates (monosaccharides). This enzyme also catalyzes the conversion of many other sugars and is primarily responsible for the type of sugar in honey (11). Diastase has an important role in assessing the quality of honey and is used as an indicator of honey purity, because the enzyme comes from the body of bees. The absence of this enzyme can be used as indicator that the honey has been adulterated. Therefore, in some countries, the activity of the diastase enzyme is used as an indicator for the purity and freshness of honey.

The data in Figure 3 show diastase enzyme activity in honey produce from the three volume treatments. The data indicated that the three treatments used in this study significantly decreased the enzyme activity. It can also be seen that for conventional cooling, the smaller the chamber volume, the higher the value of the diastase enzyme activity. However, for pasteurization and vacuum cooling treatments, different trend was observed. In this case, enzyme activity tended to decrease as chamber volume was decreased from $50 \%$ to $25 \%$, but increased significantly when chamber volume was further decreased to $12.5 \%$.

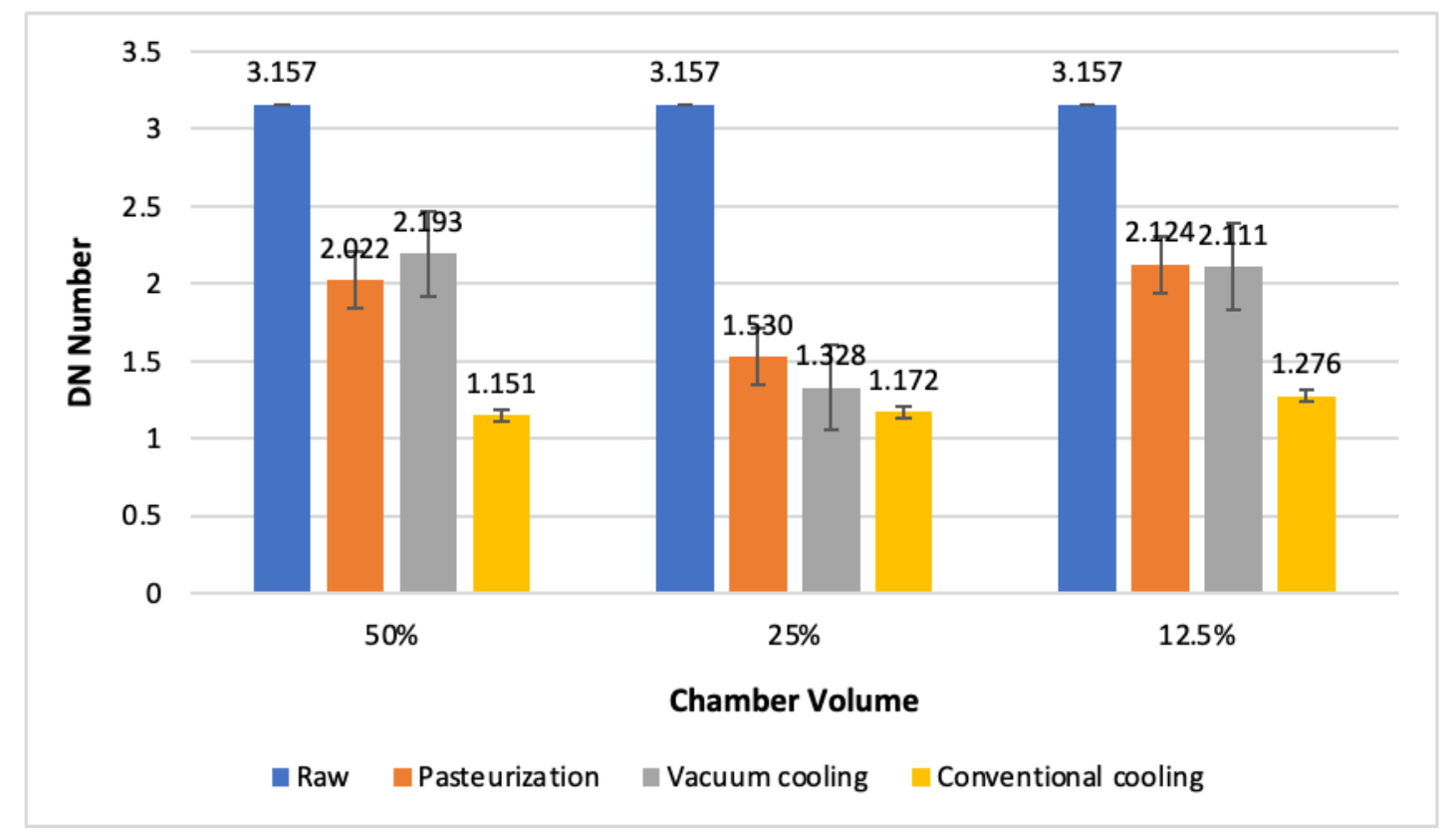

Figure 3. Riau forest honey diastase enzyme activity.

Diastase enzyme activity of honey sample produced from conventional cooling was lower than that of vacuum cooling due to the longer cooling period require for the conventional cooling. The decrease in diastase enzyme activity in Riau Forest honey was in accordance with the research of Blidi et al. (2017), which showed that heat can cause a decrease in the activity of the diastase enzyme (12). The longer the honey is exposed to high temperatures, the greater the decrease in diastase enzyme activity (13). These researchers tried to heat honey at various temperatures with 5 levels of heating time. Their results indicated that the longer the heating time, the lower the diastase enzyme activity. 
The cooling process with the highest diastase enzyme activity was found from the cooling process using vacuum cooling method at the $500 \mathrm{ml}$ chamber volume treatment. The DN values obtained from all samples of Riau Forest honey met the minimum value (1 DN) stipulated in SNI 8664:2018 standard.

\subsection{Acidity}

The acidity of honey is used as a parameter to determine whether the honey has undergone a fermentation process. Acidity is associated with the presence of organic acids that are naturally present in honey. Honey acidity is closely related to lactones, esters, ions, phosphate, sulfate ion and chloride ion contents (14). The natural acidity of honey can increase as the honey ages. In addition, exposure of honey to high temperatures can also increase acidity.

Figure 4 shows that the acidity of Riau Forest honey significantly increased after pasteurization. For $50 \%$ chamber volume, the acidity tends to decrease for vacuum cooling, but it increased for conventional cooling. The same trend was observed for $25 \%$ chamber volume. The increase the acidity might be due to water evaporation during pasteurization and cooling and due to thermal degradation of some compounds which excess hydrogen ions. The acidity of all honey samples obtained in this study met Indonesia standard (SNI $8664: 2018$ ) which stipulated that maximum acidity is $50 \mathrm{ml} \mathrm{NaOH} / \mathrm{kg}$.

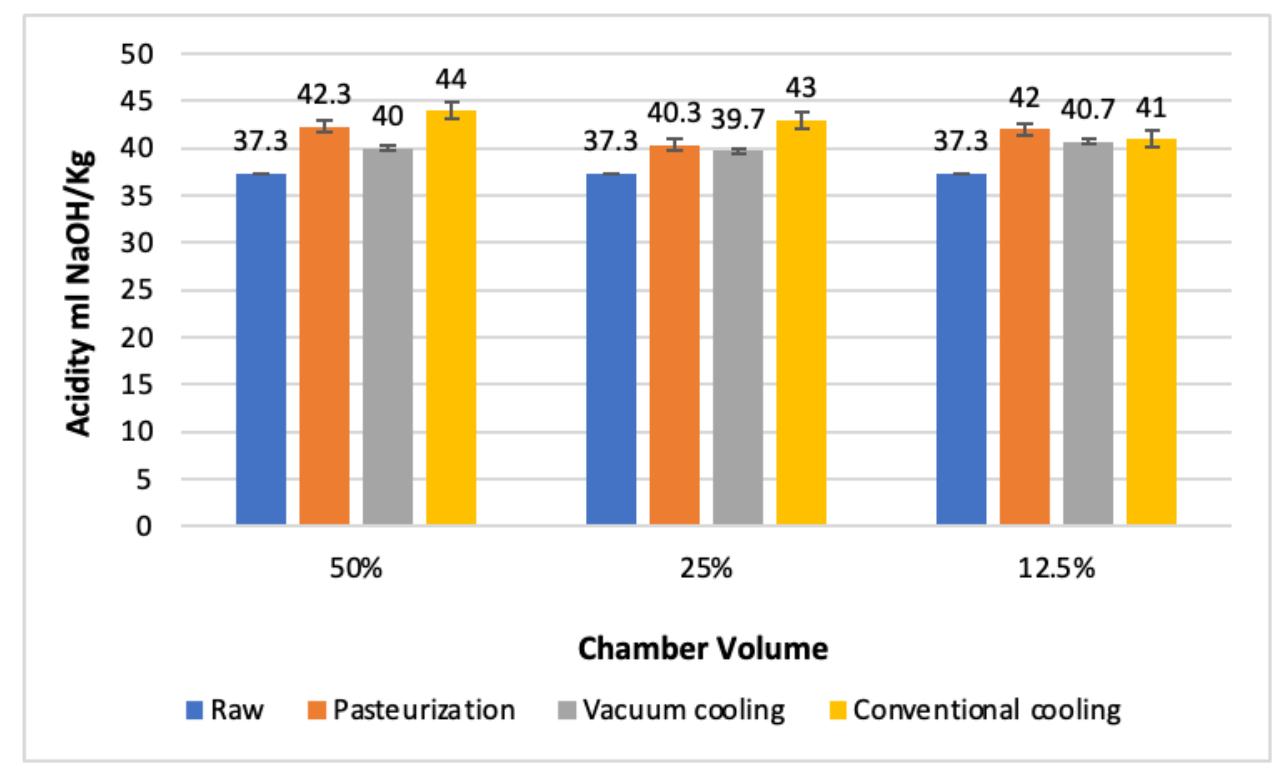

Figure 4. Riau forest honey acidity.

The higher acidity value indicates that the sample had been in contact with heat for a longer time. In the cooling process using the conventional method, the chamber volume is very influential, because the larger the volume filled with honey, the longer it takes for the honey to cool down, which causes the acidity to increase.

\section{Conclusions}

The application of the cooling process with the vacuum cooling method applied to post-pasteurized honey can reduce the cooling time. This is important because temperature 
affect several quality parameters of honey. The application of vacuum cooling also minimizes contact with air such that moisture absorption from the air can be minimized. The volume of honey in the pasteurization chamber had no significant effect on the physical properties of honey. Vacuum cooling produced better quality of honey.

\section{Acknowledgements}

The authors are grateful to SAINTEK Lastrindo engineering laboratory also CV. Lastrindo engineering for their support at all levels of experimentations.

\section{Author Contributions}

Anang Lastriyanto, Sandra Malin Sutan and Silvi Astri Cahyani conceived and designed the experiments; Anang Lastriyanto and Silvi Astri Cahyani performed the experiments; Anang Lastriyanto, Sandra Malin Sutan, Silvi Astri Cahyani, and Sumardi analysed the data; Anang Lastriyanto contributed reagents/materials/analysis tools; Silvi Astri Cahyani wrote the paper.

\section{References}

1. Badan Standardisasi Nasional (BSN). Madu SNI 8664:2018 ICS 65.020.99. 2018;27. Indonesia; 2018.

2. Subramanian R, Umesh Hebbar $H$, Rastogi NK. Processing of honey: a review. Int J Food Prop. 2007;10(1):127-43.

3. Schmidt FC, Aragão GMF, Laurindo JB. Integrated cooking and vacuum cooling of chicken breast cuts in a single vessel. J Food Eng. 2010;100(2):219-24.

4. Drummond L, Zheng L, Sun D-W. Vacuum cooling of foods. In: Emerging technologies for food processing. Elsevier; 2014. p. 477-94.

5. Escriche I, Visquert $M$, Juan-Borras $M$, Fito $P$. Influence of simulated industrial thermal treatments on the volatile fractions of different varieties of honey. Food Chem. 2009;112(2):329-38.

6. Tewodros Alemu, Eyassu Seifu, Amssalu Bezabih. Physicochemical Properties of Honey Produced in Sekota District, Northern Ethiopia. Int Food Res J. 2013;20(6):3061-7.

7. Ozturk HM, Ozturk HK, Kocar G. Comparison of vacuum cooling with conventional cooling for purslane. Int J Food Eng. 2011;7(6).

8. Wang R, Hartel RW. Effects of moisture content and saccharide distribution on the stickiness of syrups. J Food Eng [Internet]. 2020;284(March):110067. Available from: https://doi.org/10.1016/j.jfoodeng.2020.110067

9. Sande SO, Crewe RM, Raina SK, Nicolson SW, Gordon I. Proximity to a forest leads to higher honey yield: Another reason to conserve. Biol Conserv [Internet]. 2009;142(11):2703-9. Available from: http://dx.doi.org/10.1016/j.biocon.2009.06.023

10. Abdulkhaliq A, Swaileh KM. Physico-chemical properties of multi-floral honey from the West Bank, Palestine. Int J Food Prop. 2017;20(2):447-54.

11. Huang Z, Liu L, Li G, Li H, Ye D, Li X. Nondestructive determination of diastase activity of honey based on visible and near-infrared spectroscopy. Molecules. 2019;24(7):1244.

12. Blidi S, Gotsiou P, Loupassaki S, Grigorakis S, Calokerinos AC. Effect of thermal 
treatment on the quality of honey samples from Crete. Adv Food Sci Eng. 2017;1:1-8.

13. Tosi $\mathrm{E}$, Martinet R, Ortega $\mathrm{M}$, Lucero $\mathrm{H}$ and, Ré E. Honey diastase activity modified by heating. Food Chem. 2008;106(3):883-7.

14. Ratiu IA, Al-Suod H, Bukowska M, Ligor M, Buszewski B. Correlation study of honey regarding their physicochemical properties and sugars and cyclitols content. Molecules. 2020;25(1):34. 